\title{
Attitude and Knowledge of the Awareness of Missing Teeth and its Effect among Partially Edentulous Patients
}

\section{Mohril KR ${ }^{1}$ and Manekar VS2*}

${ }^{1}$ BDS, Government Dental College \& Hospital, India

${ }^{2}$ MDS, Government Dental College \& Hospital, India

*Corresponding author: Varsha Sunil M, MDS, Ph.D. Scholar, Associate professor, Government Dental College \& Hospital, Pratapnagar, Nagpur, India, Tel: 9823077626; Email: varsha@manekar.info

\section{Research Article}

Volume 3 Issue 3

Received Date: July 09, 2018

Published Date: July 18, 2018

DOI: $10.23880 /$ oajds-16000185

\section{Abstract}

Edentulism is debilitating and irreversible condition. Edentulism remains the major condition worldwide especially among adults. It is described as the final marker of the disease burden. Bone loss is ongoing process following tooth loss. Edentulism leads to resorption of the alveolar bone which in turn changes the soft tissue profile and facial appearance. Mastication is also affected by edentulism.

AIM: To evaluate the awareness of missing teeth and its effects on general and oral health among partially edentulous patients reporting to our institute.

Material \& Method: This institution based cross sectional study was done in 2016 from January to May. Sample size estimated from the cross reference was 180.

PICO: Population was the patients reported to the OPD of Department of oral diagnosis and radiology with one or more missing teeth. Intervention was the identification of partial edentulism, questionnaire filling for their awareness, counselling for the need for prosthesis. Expected outcome was increase in awareness of patients towards their partial edentulism, need of prosthesis and prosthesis options available.

Conclusion: $98.9 \%$ of the participants were aware about partial edentulous condition. $31.7 \%$ had partial knowledge and $68.3 \%$ had complete knowledge of edentulous condition. This was confirmed by clinical examination. $48.3 \%$ had difficulty in mastication followed by aesthetics and speech problems. However about 27.2\% subjects agreed that they didn't have any complaint due to missing teeth.

Keywords: Missing Teeth; Edentulous Patients; Edentulism 


\section{Open Access Journal of Dental Sciences}

\section{Introduction}

Edentulism is debilitating and irreversible condition. Tooth loss occurs due to periodontal ill health, trauma, extraction, orthodontic treatment, tooth impaction, hypoplasia etc. Edentulism remains the major condition worldwide especially among adults. It is described as the final marker of the disease burden. Bone loss is ongoing process following tooth loss. Edentulism leads to resorption of the alveolar bone which in turn changes the soft tissue profile and facial appearance. Mastication is also affected by edentulism. The mastication and the intake of food affect the nutrition status, gastrointestinal health and general condition of the individual. Hence we planned a cross-sectional study for accessing the awareness of missing teeth and its effect on the general and oral health among partial edentulous patients.

AIM is to evaluate the awareness of missing teeth and its effects on general and oral health among partially edentulous patients reporting to our institute.

\section{Objectives}

a) To assess awareness of missing teeth.

b) To analyse the awareness of various effects on general and oral health.

c) To counsel them for effect of partial edentulism and need for prosthesis.

\section{Materials and Methods}

This institution based cross sectional study was done in 2016 from January to May. Sample size estimated from the cross reference was 180 .

\section{PICO}

Population was the patients reported to the OPD of Department of oral diagnosis and radiology with one or more missing teeth. Intervention was the identification of partial edentulism, questionnaire filling for their awareness, counselling for the need for prosthesis. Expected outcome was increase in awareness of patients towards their partial edentulism, need of prosthesis and prosthesis options available.

The permission was taken from the Institutional ethical committee. A written informed consent was taken from all the participants prior to the survey. The inclusion criteria were the partial edentulous patients between the ages of 14-75 years. Exclusion criteria were completely edentulous patients, mentally and physically handicapped and non-cooperative patients were excluded from the study. The sample size calculation is done from the reference of study by Saha Adutta, et al. [1]. Relative proportion of awareness 41\%; Relative precision- 20\%; Confidence level- 95\%; Required sample size- 157\%; Assuming $10 \%$ non-response -173 . Hence 180 subjects is the sample size.

The method followed was:

a) Questionnaire for survey and feedback form were prepared and validated.

b) Identification of partially edentulous patient from OPD

c) Filling of questionnaire with consent

d) Counselling of patient with interactive session and models

e) Feedback of patients

The consent of the participant was taken. A validated self-administered questionnaire was filled by all the participants (Table 1- Questionnaire). The first part of proforma was designed to collect personal data of patient including age, sex and socioeconomic and educational status. The second part of the questionnaire consisted of 5 questions which focused on accessing the knowledge of partial edentulous condition, knowledge of effect of partial edentulous condition on oral and general health. Clinical examination of each of the participants was done to record number of missing teeth and determine reason for the loss of teeth health of periodontium and mobility of the existing teeth was also checked.

Study: Attitude and knowledge of the awareness of missing teeth and its effect among partially edentulous patients.

Consent I willing to participate in the undergoing survey 'Attitude and knowledge of the awareness of missing teeth and its effect among partially edentulous patients'. I have completely understood the terms and condition of the survey. I give my consent to publish the results.

NAME -

AGE-

SEX-

ADDRESS-

OCCUPATION - 


\section{EDUCATION -}

1) Are you aware of any missing teeth?
A)
Yes B) No

2) If yes, which and how many teeth are missing?

3) When were these teeth extracted?

4) What was the reason for the loss of the teeth?

a) Dental caries

b) Trauma

c) Teeth was extracted

d) Any other reason

5) Any difficulty faced due to missing teeth?

a) Mastication b) Poor aesthetics

c) Speech problems d) No difficulty

6) Do you think partial edentulism has effect on your general health?

a) Difficulty in weight gain b) difficulty in digestion

c) Lack of proper nutrition d) no effect

Table 1: Questionnaire.

\section{Statistical Analysis}

SPSSv16.0 was used for the data analysis. Descriptive and inferential statistics was computed. Frequency and Percentages were calculated for qualitative data. Chisqaure test was used to assess the awareness of prosthetic options in partially edentulous patients.

\section{Observations and Results}

180 partially edentulous patients were interviewed. Out of 180 subjects $13.9 \%$ were below $30 \mathrm{yrs}, 37.2 \%$ were between $30-45 y e a r s$ and $48.9 \%$ were more than 45years of the age. Out of the subjects interviewed $54.4 \%$ were females and $45.6 \%$ were males. The data further suggested that $51.7 \%$ were primary school educated, $20.6 \%$ has taken secondary school education and $27.8 \%$ were graduate or post graduate. The knowledge of edentulous condition showed a positive result that is about $98.9 \%$ were knowing about their partial edentulous state. However out of $98.9 \%$ subjects $31.7 \%$ had partial knowledge and $68.3 \%$ had complete knowledge of edentulous condition. This was confirmed by clinical examination. Table 2 shows the Frequency distribution of socio demographic characteristics and awareness of participants regarding missing teeth.

\begin{tabular}{|c|c|c|}
\hline & & Frequency (\%) \\
\hline Age & $<30$ yrs & $25(13.9)$ \\
\hline & $30-45$ yrs & $67(37.2)$ \\
\hline & $>45$ yrs & $88(48.9)$ \\
\hline & & $180(100)$ \\
\hline Sex & Male & $82(45.6)$ \\
\hline & Female & $98(54.4)$ \\
\hline Education & & $180(100)$ \\
\hline & Primary school or Illiterate & $93(51.7)$ \\
\hline & Secondary school & $37(20.6)$ \\
\hline & Junior college or higher & $50(27.8)$ \\
\hline Knowledge about missing teeth & & $180(100)$ \\
\hline & Yes & $178(98.9)$ \\
\hline & No & $2(1.1)$ \\
\hline Knowledge about missing teeth & Partially know & $180(100)$ \\
\hline
\end{tabular}




\section{Open Access Journal of Dental Sciences}

\begin{tabular}{|c|c|c|}
\hline & Completely know & $123(68.3)$ \\
\hline & & $180(100)$ \\
\hline Time lapsed after missing teeth & & $5.66(3.24)$ \\
\hline Reason for missing teeth & Caries & $109(60.9)$ \\
\hline & Trauma & $23(12.8)$ \\
\hline & Extraction & $26(14.5)$ \\
\hline & Any other & $16(8.9)$ \\
\hline & Combination & $5(2.8)$ \\
\hline Complaints due to missing teeth & Difficulty in mastication & $180(100)$ \\
\hline & Poor esthetics & $19(48.3)$ \\
\hline & Difficulty in speech & $3(1.7)$ \\
\hline & No problem & $49(27.2)$ \\
\hline & Combination & $22(12.2)$ \\
\hline & & $180(100)$ \\
\hline & Reduced weight & $1(0.6)$ \\
\hline & Difficulty in digestion & $19(10.60$ \\
\hline & Insufficient nutrition & $31(17.2)$ \\
\hline & Know about all & $4(2.2)$ \\
\hline & None of the above & $123(68.3)$ \\
\hline & Combination & $2(1.1)$ \\
\hline & & $180(100)$ \\
\hline
\end{tabular}

Table 2: Frequency distribution of socio demographic characteristics and awareness of participants regarding missing teeth.

Dental caries was the major reason for the loss of the teeth which contributed about $60.9 \%$. This was followed by periodontal problems (14.5\%), trauma (12.8\%), and other reasons for the loss of the teeth (8.9\%). About $2.8 \%$ had more than one reason for the tooth loss. Refer to Table 1 . When asked about difficulty faced due to missing teeth majority of participants that is about $48.3 \%$ had difficulty in mastication. Aesthetics was issue in about $10.6 \%$ and about $1.7 \%$ complained about difficulty in speech. $12.2 \%$ subjects faced multiple problems.

On Inspection of data regarding effects of partial edentulous condition on systemic health. Majority of the participants that is about $68.3 \%$ were of the opinion that there is no any systemic effect. $17.2 \%$ agreed that lack of proper nutrition would be the problem since there is impairment in chewing. Difficulty in digestion was complaint of about $10.6 \%$ of subjects. About $2.2 \%$ agreed that partial edentulism would lead to reduced weight, difficulty in digestion and insufficient nutrition [2].

\section{Discussion}

Kathleen D' souza, et al. [3] and Nadia Khalifa [4] found that prevalence of partial edentulism is slightly more in females $(54.9 \%)$ and slightly less in males (45\%). The study by Isha Rastogi [5] infers that not marked sex predilection is observed as per the tooth loss is concerned. This study showed similar results.

Accordingly Kathleen D' Souza, et al. [3] and Isha Rastogi [5] in their respective study showed that subjects with basic educational group contributed majority with partial edentulous state. Nadia Khalifa, et al. [4] in the study also shows congruent results as per the educational status is considered. This study enlightens similar result i.e., $51.7 \%$ of subjects with basic educational group were partially edentulous. Literacy plays important role to maintain proper oral health and in turn the tooth loss. 98.9\% subjects had knowledge of missing teeth. $68.3 \%$ out of them had complete knowledge about missing teeth.

In the present study caries $(60.7 \%)$ contributed mainly to loss of the tooth followed by periodontal reasons (14.5\%), trauma (12.8). According to the study by D'souza, et al. [3] reasons for tooth loss predominantly was dental caries i.e., $83.85 \%$, periodontal reason $10.25 \%$, trauma 5.28\%. According to study by Prabhu, et al. \& Isha Rastogi, et al. [5]. Dental Caries was primary reasons for tooth loss, followed by periodontal and traumatic reasons. Simhachalan Reddy [6] conducted a study which inferred that major reason for tooth loss was dental caries $(37.45 \%)$. In the research on analysis for reasons for extraction by Manekar, et al. [7] 55.67\% tooth was extracted due to dental caries and its sequel, second most 


\section{Open Access Journal of Dental Sciences}

common reason was periodontal disease $(23.59 \%)$. The results are congruent with the above mentioned studies.

In study by Kathlin D'souza [3] found that mastication was chiefly affected due to partial edentulous condition i.e., $57.45 \%$ followed by aesthetics , speech and $34.4 \%$ subjects were of the opinion that more than one function was affected. Isha Rastogi, et al. [4] also concluded that mastication was the major problem faced by the subjects. Results of this study go hand in hand with previous studies i.e., $48.3 \%$ had difficulty in mastication followed by aesthetics and speech problems. Simhachalam Reddy [6] in his study concluded that mastication was major problem following the tooth loss, however $27.2 \%$ subjects agreed that they didn't have any complaint due to missing teeth.

Mastication being the foremost step in the digestion. Improper mastication affects digestion. Moreover inability to chew further forces the patient to consume overcook food which lacks nutritional value [8]. Elham Emami, et al. [9] has stated that partial edentulous condition have various systemic effects and increased in mortality rate. However according to this study about $68.3 \%$ subjects were not aware of any systemic effect. $17 \%$ agreed that partial edentulous state may lead to insufficient nutrition [10-12].

\section{Conclusion}

One study has stated: "Oral diseases are the fourth most expensive to treat in most industrialized countries. Were it available in many low-income countries, treatment of dental caries in children alone would exceed the total child health care budget" [13]. Majority of the subjects were knowing about partial edentulous condition but were reluctant to replace the teeth. Lack of awareness regarding effects of edentulism on general and oral health, lack of awareness about prosthetic options, financial difficulties, previous bad experience and myths may be the few reasons for not opting for treatment. Removable partial denture, fixed partial denture and Dental implant supported prosthesis are the treatment options available for replacement of missing teeth. However efforts should be taken to make this treatment more cost effective.

Prevention is better than cure. Since Dental Caries contributes maximum to tooth loss, primary preventive measures such as Diet counselling, fluoride application, regular dental checkups and early detection and restoration of caries can significantly reduce the tooth loss. Patient's motivation for proper oral hygiene habits can be helpful to decrease the tooth loss. Most of the subjects was of opinion that partial edentulous condition doesn't have any systemic effect. Hence there is the need to increase the awareness among the people regarding the effects of oral condition on systemic health through various public health programs and awareness programs. Media and digital technology can be the powerful tool to enhance awareness in the society.

\section{Limitation}

The study was institutional based and this might have biased the results as the selected subject does not represent the population. The study does not specify the problems faced by the subjects depending on the region of the tooth loss.

\section{References}

1. Vadavadagi SV, Srinivasa H, Goutham GB, Hajira N, Lahari M (2015) Partial edentulism and its association with socio-Demographic variables among subjects Attending Dental Teaching Institutions, India. J Int Oral Health 7(2): 60-63.

2. Ashistaru Saha, Sudipto Dutta, Vijaya V, Rajnikant N (2013) Awareness among patients regarding implant as treatment options for replacement of missing teeth in Chattisgarh. J Int Oral Health 5(5): 48-52.

3. D'Souza KM, Aras M (2014) Association between socio-demographic variables and partial edentulism in the Goanpopulation: An epidemiological study in India. Indian J Dent Res 25(4): 434-438.

4. Nadia Khalifa, Allen PF, Abu-bakr NH, Abdel-Rahman ME (2012) Factors associated with tooth loss and prosthodontic status among Sudanese adults. J Oral Sci 54(4): 303-312.

5. Isha Rastogi, Abhishek M, Yash A, Shashi Shekhar Mishra (2017) Assessment of Prosthodontic Awareness and Edentulism in Populations of Lucknow-A Clinical Survey. Int J Dent \& Oral Heal 3(3): 23-30.

6. Simhachalam RN (2010) Edentulism-An Epidemiological Survey of Population in Chennai, India.J Orofacial Sciences 2(1): 14-18.

7. Varsha Sunil M, Prajwalit K, Seema Kulkarni (2015) Tooth Mortality: An Analysis of Reasons underlying the Extraction of Permanent Teeth. World Journal of Dentistry 6(2): 93-96. 
8. Vaishnavi R, Padma A, Dhanraj M, Ashish RJ (2018) Effect of edentulism on general health and quality of life. Dental invention today 10(4): 549-553.

9. Elham Emami, Raphael, Fretus de Souza Marla Kabawat (2013) The Impact of edentulism on Oral and general health. Int J Dent 2013: 498305.

10. N'gom PI, Woda A (2002) Influence of impaired mastication on nutrition. J Prosthet Dent 87(6): 667673.

11. Ritchie CS, Joshipura K, Hung HC, Douglass CW (2002) Nutrition as a mediator in the relation between oral and systemic disease: associations between specific measures of adult oral health and nutrition outcomes. Crit Rev Oral Biol Med 13(3): 291-300.

12. Chauncey HH, Muench ME, Kapur KK, Wayler AH (1984) The effect of the loss of teeth on diet and nutrition. Int Dent J 34(2): 98-104.

13. Petersen PE (2004) Improvement of oral health in Africa in the $21^{\text {st }}$ century - the role of the WHO Global Oral Health Programme. Developing Dentistry 5(1): 9-20. 